\title{
Improving the Life Time of the Wireless Sensor Network Using Fuzzy Logic
}

Anjamma Onteru

Deportment: Electronics and Communication Engineering, J.N.T.U Ananthapur, JNTUCEA, Andhra Pradesh, India

\begin{abstract}
In the past few years, intensive research that addresses the potential of collaboration among sensors in data gathering and processing, and coordination and management of the sensing activity was conducted. Thus, innovative techniques to eliminate energy inefficiencies that shorten the lifetime of the Network and efficient use of the limited bandwidth are highly required. LEACH (Low Energy Adaptive Clustering Hierarchy) is the most famous routing protocol which consumes less energy. In LEACH, the Cluster Head is selected based on some random probabilities. These Cluster Heads send the aggregated data to the base station. In the proposed protocol, Cluster Heads are selected in the same procedure followed by the LEACH. But, among the Cluster Heads, we have selected a Super Cluster Head (SCH) based on some fuzzy descriptors such as remaining battery power, centrality of cluster heads and mobility of base station. The Super Cluster Head then sends the data to the base station. The results have been derived from NS-2 simulator and show that the proposed protocol performs better than the LEACH protocol.
\end{abstract}

Keywords : LEACH, CH, SCH, fuzzy logic, NS- 2 Simulator.

\section{INTRODUCTION}

Wireless Sensor Network considered as real time embedded system deployed in a particular region to sense various types of environmental parameters such as temperature, pressure, gas, humidity etc. The huge applications of WSN like habitant monitoring, forest fire detection, surveillances, transport monitoring etc. have created a lot of interest among the researcher community in recent past. Typically, WSNs are densely deployed in hazardous places where battery recharge or replacement is nearly impossible and human monitoring scheme is highly risky. Once the network is established, nodes keep on sensing the information and the battery power goes exponentially. Whenever the nodes detect any event, they send the information to the other nodes or to the base station. Sometimes it happens that the same information received by nearby sensor nodes can be received by the base station that makes the network in efficient. Cluster based routing protocol is one of these efficient ideas, where sensor nodes are divided into number of groups and each group is called as a cluster. One group leader is elected in each cluster known as Cluster Head $(\mathrm{CH})$. Data aggregation is obtained at the leader node. The leader node $(\mathrm{CH})$ is only responsible for sending the message to the BS.

\section{RELATED WORK}

\section{LEACH Protocol:}

LEACH stands for Low-Energy Adaptive Clustering Hierarchy. It is TDMA based MAC protocol. In LEACH, the nodes are organize themselves into local clusters, with one node acting as the cluster head. LEACH performs local data aggregation to "compress" 
the amount of data being sent from the clusters to the base station .So reducing energy dissipation and enhancing system lifetime. The operation of LEACH is divided into rounds. Each round contains two phases: Set-up phase

Steady-state phase

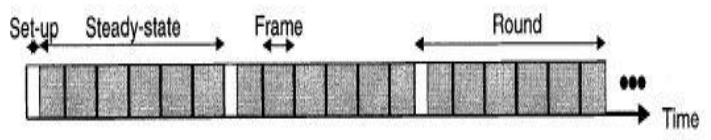

Fig 1: Setup and Steady phases

To minimize overhead, the steady-state phase is long compared to the set-up phase.

\section{- Setup Phase:}

In this phase select cluster head and form the clusters by choosing the node with maximum energy

Steps:

1. Cluster Head Advertisement

2. Cluster setup

3. Creation of TDMA schedule

\section{- Steady State Phase:}

1. Cluster nodes send data to $\mathrm{CH}$

2. $\mathrm{CH}$ aggregates all the collected data and send to the BS.

Cluster Head :

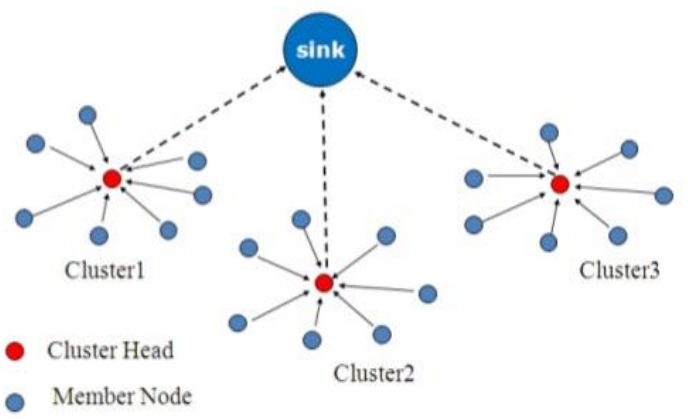

Fig 2 : LEACH Architecture

\section{Cluster Formation:}

$\mathrm{CH}$ sends join advertisement message to all the non cluster head nodes in the network using MAC protocol. Non $\mathrm{CH}$ nodes sends join request message to CH's based on the requirement of communication energy. The cluster head node sets up a TDMA schedule and transmits this schedule to the nodes in the cluster. Due to this the radio components of each non-cluster head node to be turned off at all times except during their transmit time.

\section{Limitations:}

- In LEACH each cluster head collects data from nodes and send to base station. So, energy consumption is more.

- If the elected node is located near to the boundary of the network, other nodes could dissipate more energy to transfer the message to $\mathrm{CH}$.

\section{PROPOSED SYSTEM}

Fuzzy Logic is used to model human experience and human decision making behavior. Further, it can handle uncertainties of real time applications more accurately than the probabilistic model .Applying suitable fuzzy descriptors to improve the performance of LEACH protocol in view of electing an appropriate Super Cluster Head (SCH) among the CHs. Fuzzy Logic is adopted in this technique in order to handle the uncertainties for electing the SCH. Instead of multiple $\mathrm{CHs}$, one $\mathrm{SCH}$ can deliver the message to $\mathrm{BS}$ that can reduce the energy consumption and enhances energy efficiency. It is assumed that sensor nodes send the data after detecting an interesting event. $\mathrm{CH}$ collects these data, aggregates it and send to the base station. To save some energy, we may think of one SCH among the CHs can send the data to BS to utilize the bandwidth efficiently. Instead of multiple CHs, one $\mathrm{SCH}$ can deliver the message to $\mathrm{BS}$ that can reduce energy consumption and enhances energy efficiency. 
Further assumption we have made that Remaining battery power, Mobility, Centrality. The three fuzzy descriptors are suitable to calculate the chance to be $\mathrm{SCH}$ that can deliver the message to the BS.

\section{Fuzzy Inference System:}

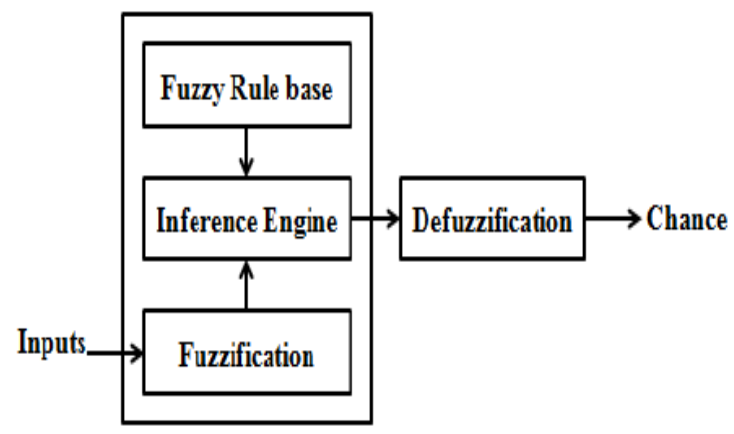

Fig 3: Block diagram of Fuzzy Inference System

1.Fuzzification: In fuzzifier, inputs are given with crisp value and changed into a fuzzy set. This can be achieved by fuzzification.

2. Rule Evaluation: It stores IF-THEN rule.

3. Fuzzy Inference Engine: This engine takes both the input values and IF-THEN rules to simulate the reasoning by which it produces a fuzzy inference.

4. Defuzzification: Defuzzifier transforms the fuzzy set into crisp value.

Input parameters of fuzzy logic controller in the proposed method are:

- Remaining battery power: The energy level available in each node.

- Mobility: The BS moves in a particular direction, the distance between BS and SCH increases or decreases w.r.t to the speed and direction of moving BS

- Centrality: A value which classifies the nodes based on how central the node is to the cluster.

Output parameter:

\section{- Chance $=$ (Remaining battery power $)+$}

mobility+ centrality

Language variables for each of the inputs and output are:

Table 1: Membership functions for inputs and output parameters

\begin{tabular}{|l|l|l|l|}
\hline $\begin{array}{l}\text { Remaining } \\
\text { battery power }\end{array}$ & Mobility & Centrality & chance \\
\hline Less(0) & Low(0) & Close(0) & Very Weak(-1) \\
\hline Medium(1) & Moderate(1) & Adequate(1) & Weak(0) \\
\hline High(2) & Frequent(2) & Far(2) & $\begin{array}{l}\text { Lower } \\
\text { Medium(1) }\end{array}$ \\
\hline & & & medium (2) \\
\hline & & & $\begin{array}{l}\text { Higher } \\
\text { Medium(3) }\end{array}$ \\
\hline & & & Strong (4) \\
\hline & & & Very strong(5) \\
\hline
\end{tabular}

\section{Membership Functions:}

The membership functions and their corresponding linguistic states:

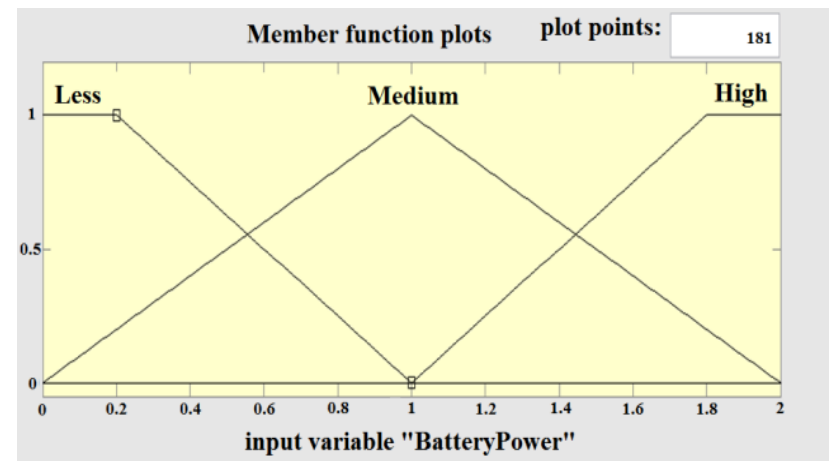

Fig 4 : Battery Power

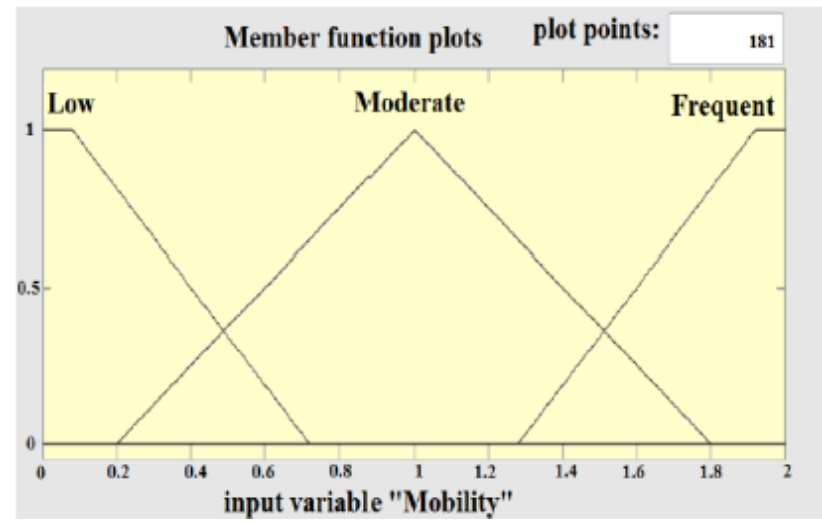

Fig 5: Mobility 


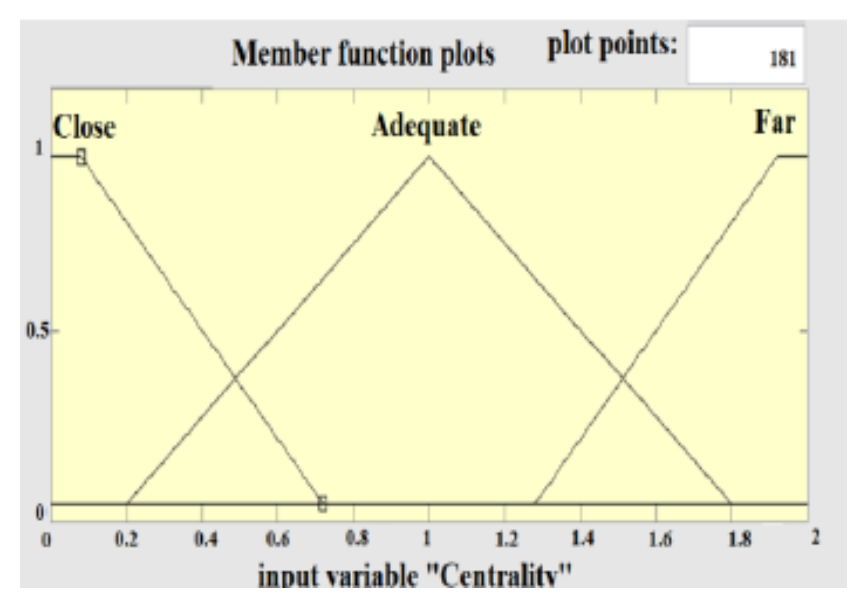

Fig 6: Centrality

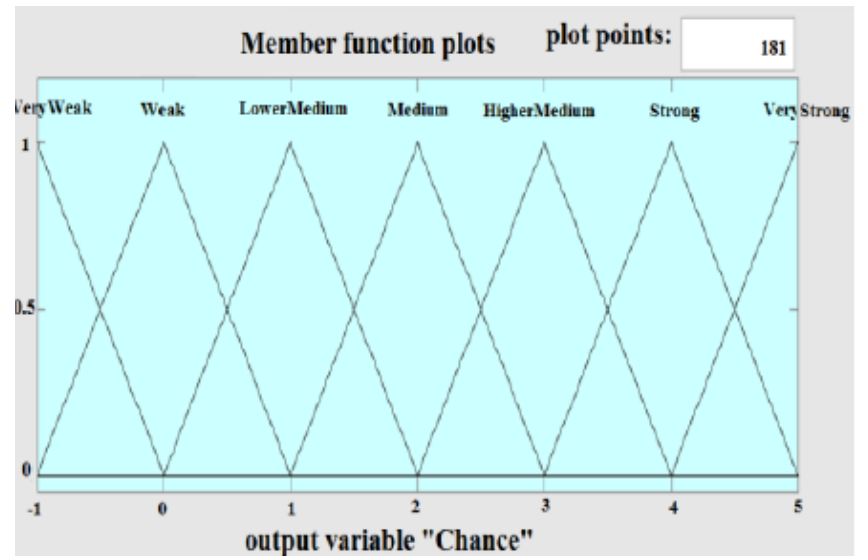

Fig 7: Chance

Fuzzy Rule Base:

The chance value to be the $\mathrm{SCH}$ is calculated considering three input parameters such as remaining battery power, mobility and centrality by using Fuzzy rules. In our system, we have used 27 rules in the fuzzy inference.

Table 2 : Fuzzy Rules and Value of Chance

\begin{tabular}{|c|c|c|c|}
\hline $\begin{array}{l}\text { Remaining } \\
\text { Battery } \\
\text { Powrer }\end{array}$ & Mobility & Centrality & Chance \\
\hline Less (0) & Low $(0)$ & Close (0) & Very Weak (-1) \\
\hline Less (0) & Low (0) & Adequate(l) & Weak (0) \\
\hline Less (0) & Law (0) & Far (2) & LowerMedium (1) \\
\hline Less (0) & Moderate (1) & Clase (0) & Weak (0) \\
\hline Less (0) & Moderate (1) & Adequate (1) & Lower Medium (1) \\
\hline Less $(0)$ & Moderate (1) & Far (2) & Medium (2) \\
\hline Less (0) & Frequent(2) & Clase (0) & Lower Medium (1) \\
\hline Less (0) & Frequent (2) & Adequate (1) & Medium (2) \\
\hline Less (0) & Frequent(2) & Far (2) & Higher Medium (3) \\
\hline Medium (1) & Low $(0)$ & Clase (0) & Weak (0) \\
\hline $\operatorname{Medium(1)}$ & Low $(0)$ & Adequate(1) & LowerMedium (1) \\
\hline Medium (1) & Low (0) & Far (2) & Medium (2) \\
\hline Medium (1) & Moderate (1) & Close (0) & LowerMedium (1) \\
\hline $\operatorname{Medium}(1)$ & Moderate (1) & Adequate (l) & Medium (2) \\
\hline Medium (1) & Moderate (1) & Far (2) & Higher Medium (3) \\
\hline Medium (1) & Frequent (2) & Close (0) & Medium (2) \\
\hline $\operatorname{Medium}(1)$ & Frequent(2) & Adequate (1) & Higher Medium (3) \\
\hline Medium (1) & Frequent (2) & Far (2) & Strong (4) \\
\hline High (2) & Law (0) & Close (0) & Lower Medlum (1) \\
\hline High (2) & Low (0) & Adequate(1) & Medium (2) \\
\hline High (2) & Low $(0)$ & $\operatorname{Far}(2)$ & Higher Medium (3) \\
\hline High (2) & Moderate (1) & Close (0) & Medium (2) \\
\hline High (2) & Moderate (1) & Adequate(l) & Higher Medium (3) \\
\hline High (2) & Moderate (1) & Far (2) & Strong (4) \\
\hline High (2) & Frequent (2) & Close (0) & Higher medium (3) \\
\hline High (2) & Frequent(2) & Adequate(1) & Strong (4) \\
\hline High (2) & Frequent (2) & Far (2) & Very Strong (5) \\
\hline
\end{tabular}

\section{SIMULATION}

To check the validity of the proposed protocol, NS-2 simulator (2.34) tool is used to compare the performance metrics of LEACH protocol which ensures extended lifetime of the WSN for the proposed protocol.

\section{Simulation Parameters:}

Table 3 : Simulation Parameters of the Network

\begin{tabular}{|l|l|}
\hline Parameter & Value \\
\hline Network Size & $500 \mathrm{~m} \times 500 \mathrm{~m}$ \\
\hline No. of nodes & 50 \\
\hline No. of cluster heads & 3 \\
\hline BS location & $250 \mathrm{~m} \times 250 \mathrm{~m}$ \\
\hline Node distribution & Random \\
\hline BS Mobility & Random Walk \\
\hline Channel & Wireless \\
\hline Simulation Time & 50 sec \\
\hline Bandwidth & $1 \mathrm{Mbps}$ \\
\hline Packet size & 512 bytes \\
\hline
\end{tabular}




\section{RESULTS AND DISCUSSION}

In this section, we present the experimental results obtained from the simulations to evaluate the proposed algorithm. In fig : calculate the average throughput of the network w.r.t number of nodes and in fig : the total residual energy of the network w.r.t number of nodes to both LEACH and proposed systems.

NAM: Network Animator Window

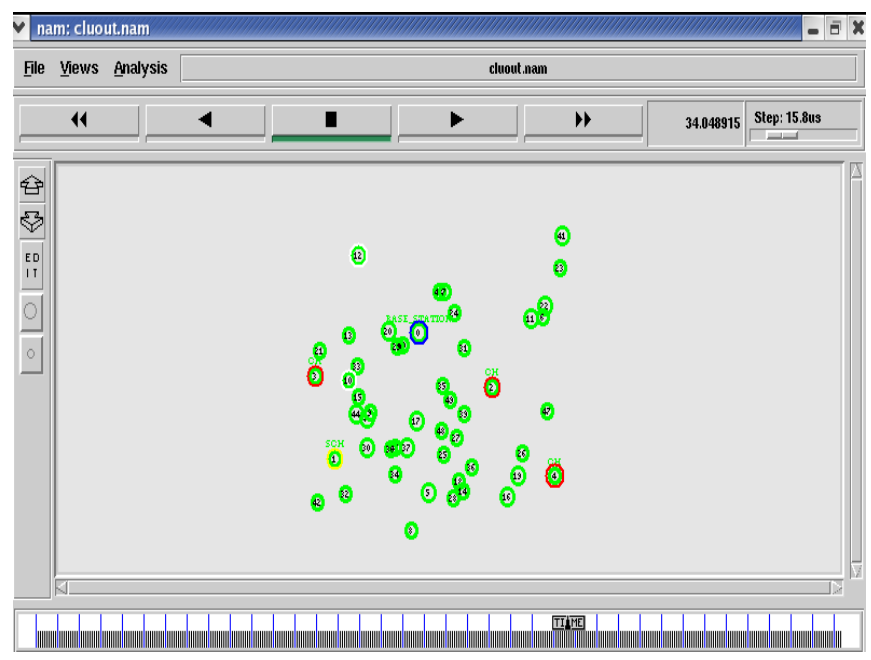

Fig 8: NAM output

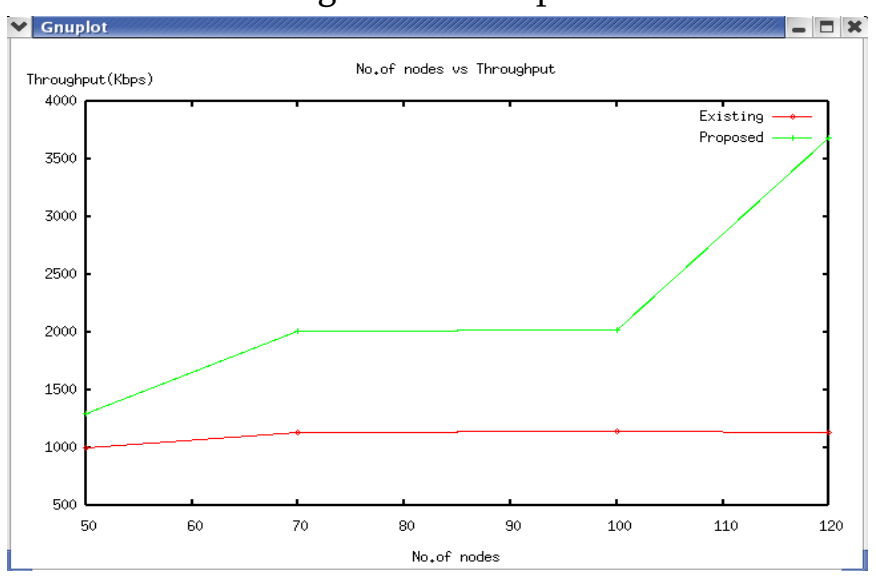

Fig 9: No. of nodes Vs Throughput

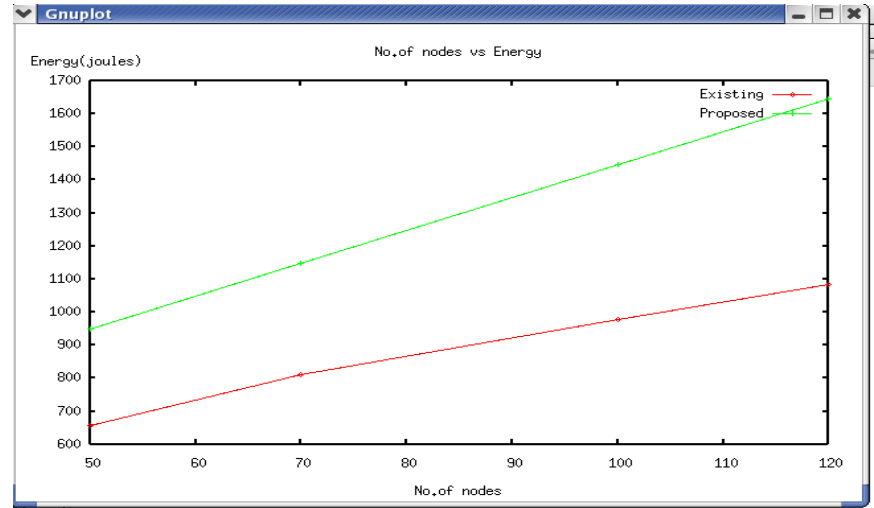

Fig 10: No of nodes Vs Energy of the network

Table 4: Comparison of Average Throughput

\begin{tabular}{|l|l|l|}
\hline Number of nodes & LEACH(kbps) & FUZZY LOGIC(kbps) \\
\hline 50 & 996.28 & 1297 \\
\hline 70 & 1125 & 2013 \\
\hline 100 & 1141.5 & 2018 \\
\hline 120 & 1127 & 3686 \\
\hline
\end{tabular}

Table 5: Comparison of Total Residual Energy

\begin{tabular}{|l|l|l|}
\hline Number of nodes & LEACH(joules) & $\begin{array}{l}\text { FUZZY } \\
\text { LOGIC(joules) }\end{array}$ \\
\hline 50 & 656.06 & 948.32 \\
\hline 70 & 810.47 & 1146.62 \\
\hline 100 & 978.09 & 1445.88 \\
\hline 120 & 1083.81 & 1645.17 \\
\hline
\end{tabular}

\section{v. CONCLUSION}

The summary of the system is "Performance comparison of Fuzzy based clustering protocol with LEACH routing protocol for Wireless Sensor Network applications" is that we have considered a novel approach to develop a new clustering protocol which is more efficient than the existing LEACH clustering protocol, In this protocol, we have considered three fuzzy parameters such as mobility, node energy, centrality to select the super cluster head among the cluster heads so that super cluster head can send the 
data to the base station with most effective and efficient manner. Further we have considered the performance metrics such as Average throughput and energy of the network of the LEACH and our proposed protocol using NS-2 simulator. From this simulation results, it is concluded that our proposed protocol works better than LEACH. The simulations are done using NS -version (2.34) and the results are analyzed through gnuplot.

\section{REFERENCES}

[1]. Padmalaya Nayak and D.Anurag "A Fuzzy Logic based Clustering Algorithm for WSN to extend the Network Lifetime" IEEE Sensors Journal,2015.

[2]. W. R. Heinzelman, A. Chandrakasan, and H. Balakrishnan, Energy-efficient Communication Protocol for Wireless Microsensor Networks., in IEEE Computer Society Proceedings of the Thirty Third Hawaii International Conference on System Sciences (HICSS '00), Washington, DC, USA, Jan. 2000, vol. 8, pp. 8020.

[3]. W. R. Heinzelman, A. Chandrakasan and H. Balakrishnan,"An application-specific protocol architecture for wireless microsensor networks," in IEEE Transactions on Wireless Communications, Oct. 2002, pp. 660 - 670

[4]. I. Gupta, D. Riordan and S. Sampalli, "Cluster head Election using Fuzzy Logic for Wireless Sensor Networks", Communication Networks and Services Rearch Conference, pp.255-260, May 2005.

[5]. Jong-Myoung Kim, Seon-Ho Park, Young-Ju Han, TaiMyoung Chung," CHEF: Cluster Head Election mechanism using Fuzzy logic in Wireless Sensor Networks "ICACT 2008,PP-654659, feb 2008.

[6]. Abhijeet Alkesh, Ashutosh Kumar Singh, N.Purohit, "A moving base station strategy using fuzzy logic for life time enhancement in wireless sensor network", in proc. of International Conference on Communication Systems and Network Technologies, 2011, pp 198-202,

[7]. Hoda Taheri et.al., "An energy-aware distributed clustering protocol in wireless sensor networks using fuzzy logic", Adhoc Networks 10 (2012) 1469-1481.

[8]. Tripti Sharma, Brijesh Kumar, "F-MCHEL: Fuzzy Based Master Cluster Head Election Leach Protocol in Wireless Sensor Network", International Journal of Computer Science and Telecommunications, Volume 3, Issue 10, October 2012, pp.8-13.

[9]. Z.W.Siew, C.F.Liau, A.Kiring, M.S. Arifianto, K.T.K. Teo, "Fuzzy Logic Based Cluster Head Election for Wireless Sensor Network", in Proc. of 3 rd CUTSE International Conference, Malaysia, 2011, pp. 301-306.

[10]. Vibha Nehra, Raju Pal, Ajay K Sharma, "Fuzzybased Leader Selection for Topology Controlled PEGASIS Protocol for Lifetime Enhancement in Wireless Sensor Network", International Journal of Computers \& Technology, Volume 4 No.3, March-April, 2013, ISSN 2277-3061, pp755-764.

[11].GeRan, Huazhong Zhang, Shulan Gong, "Improving on LEACH Protocol of Wireless Sensor Networks Using Fuzzy Logic", Journal of Information \& Computational Science 7: 3 (2010) 767-775.57.

Cite this article as : Anjamma Onteru, "Improving the Life Time of the Wireless Sensor Network Using Fuzzy Logic", International Journal of Scientific Research in Science and Technology (IJSRST), Online ISSN : 2395602X, Print ISSN : 2395-6011, Volume 6 Issue 2, pp. 320-325, March-April 2019. Available at doi : https://doi.org/10.32628/IJSRST196257 Journal URL : http://ijsrst.com/IJSRST196257 